\title{
The JAK/STAT Pathway
}

\section{Douglas A. Harrison}

Department of Biology, University of Kentucky, Lexington, Kentucky 40506

Correspondence: DougH@uky.edu

Cellular responses to dozens of cytokines and growth factors are mediated by the evolutionarily conserved Janus kinase/signal transducers and activators of transcription (JAK/STAT) signaling pathway (Fig. 1). These responses include proliferation, differentiation, migration, apoptosis, and cell survival, depending on the signal, tissue, and cellular context. JAK/STAT signaling is essential for numerous developmental and homeostatic processes, including hematopoiesis, immune cell development, stem cell maintenance, organismal growth, and mammary gland development (Ghoreschi et al. 2009).

Janus kinases (JAKs) were identified through sequence comparisons as a unique class of tyrosine kinases that contain both a catalytic domain and a second kinase-like

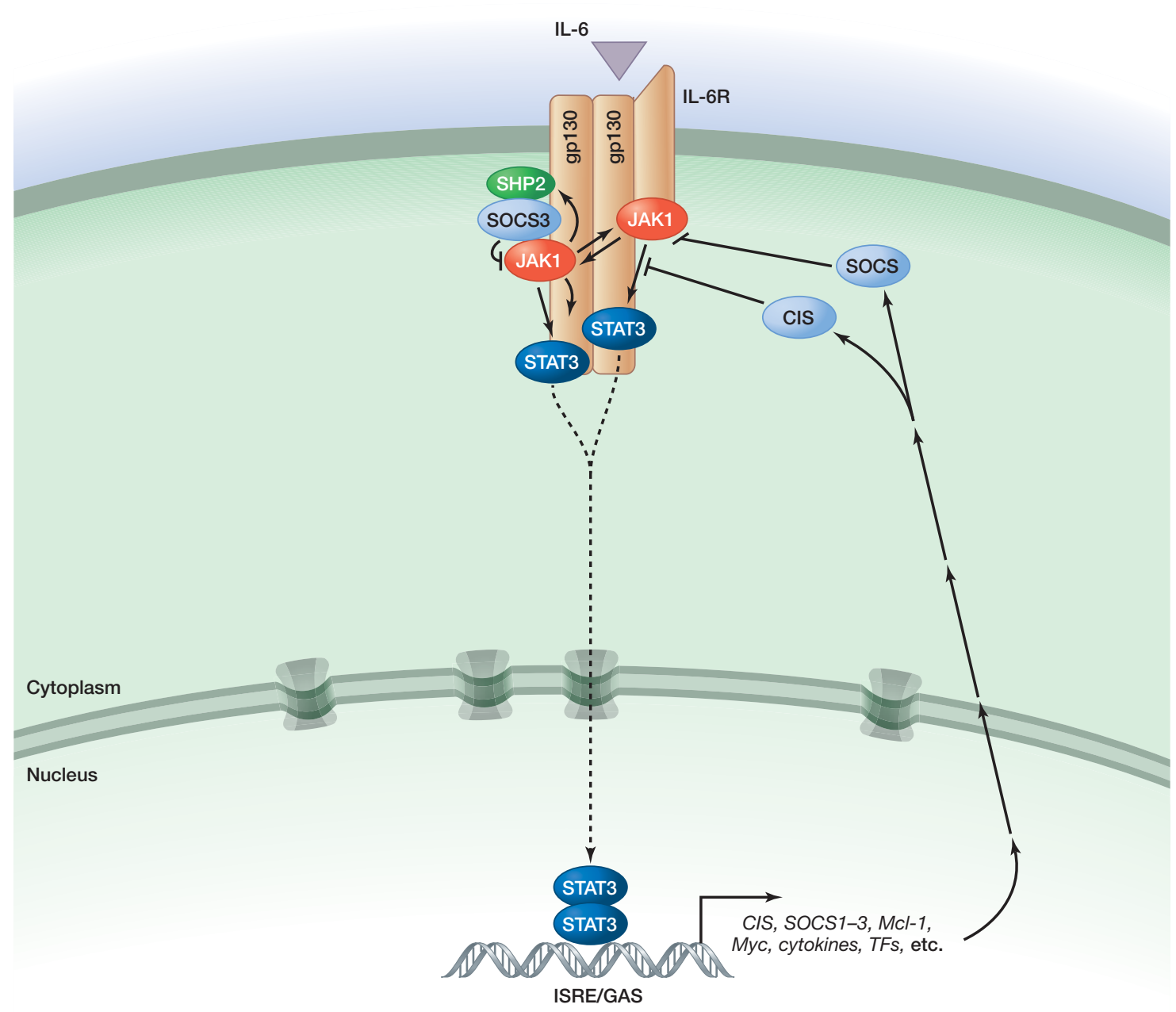

Figure 1. The JAK/STAT pathway (simplified view). 
domain that serves an autoregulatory function, hence the homage to the two-faced Roman god. They were functionally linked to STATs and interferon signaling in powerful somatic cell genetic screens (Darnell et al. 1994; Schindler and Plumlee 2008). The JAK/STAT cascade is among the simplest of the conserved metazoan signaling pathways. The binding of extracellular ligand leads to pathway activation via changes to the receptors that permit the intracellular JAKs associated with them to phosphorylate one another. Trans-phosphorylated JAKs then phosphorylate downstream substrates, including both the receptor and the STATs. Activated STATs enter the nucleus and bind as dimers or as more complex oligomers to specific enhancer sequences in target genes, thus regulating their transcription (Fig. 2).

In mammals, there are four members of the JAK family and seven STATs. Different JAKs and STATs are recruited based on their tissue specificity and the receptors engaged in the signaling event (Schindler and Plumlee 2008). In invertebrates, the Drosophila JAK/STAT pathway has been extensively studied and comprises only one JAK and one STAT (Arbouzova and Zeidler 2006). Although the canonical JAK/STAT pathway is simple and direct, pathway components regulate or are regulated by members of other signaling pathways, including those involving the ERK MAP kinase, PI 3-kinase (PI3K), and others. Furthermore, non-canonical JAK and STAT activities influence the global transcriptional state through modification of chromatin structure (Li 2008; Dawson et al. 2009).

Human JAK mutations cause numerous diseases, including severe combined immune deficiency, hyperIgE syndrome, certain leukemias, polycythemia vera, and other myeloproliferative disorders (Jatiani et al. 2010). Because of the causative role in these diseases and their central significance in immune response, JAKs have become attractive targets for development of therapeutics for a variety of hematopoietic and immune system disorders (Pesu et al. 2008; Haan et al.

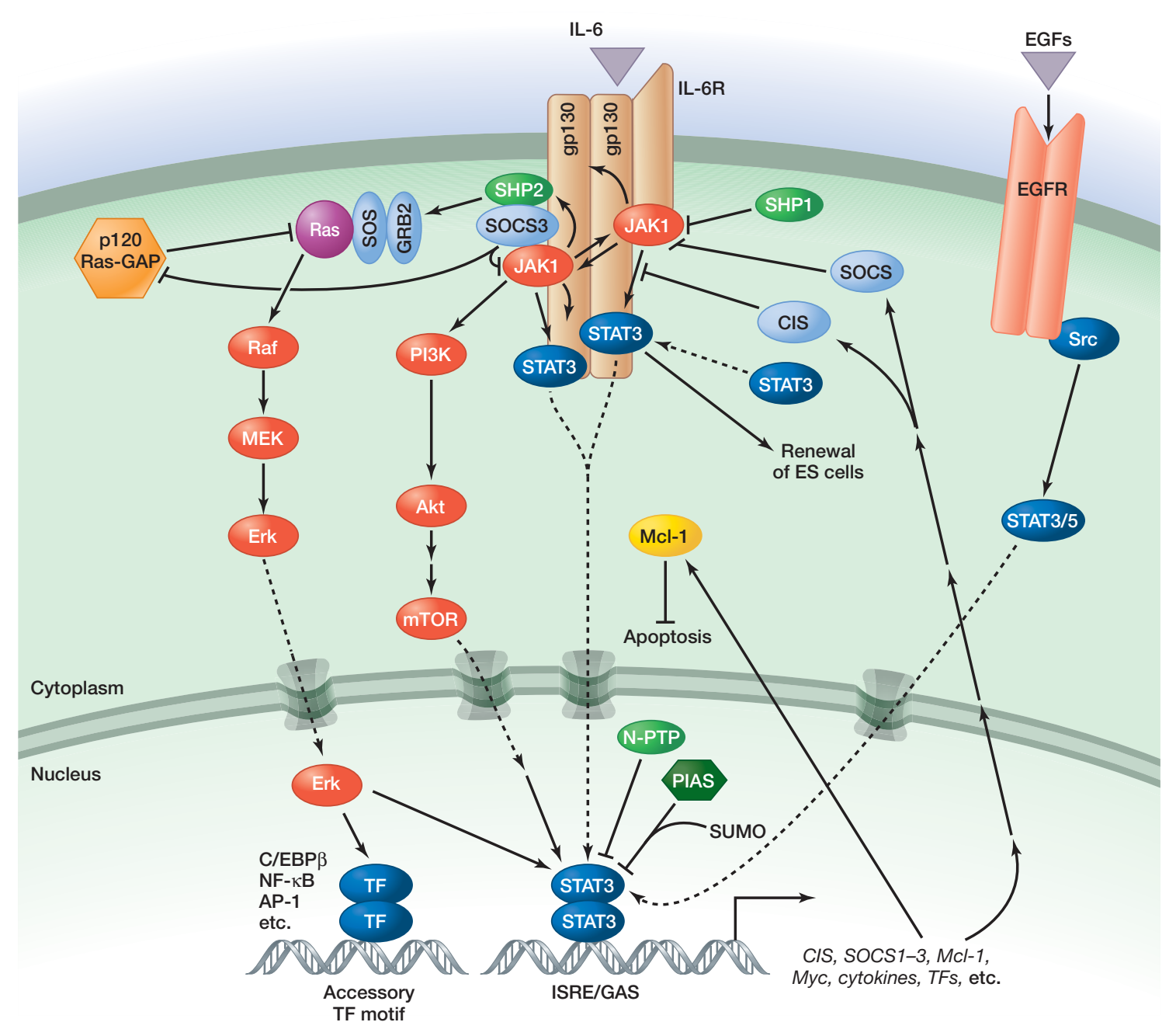

Figure 2. The JAK/STAT pathway. 
2010). Owing to the pleiotropy of the JAK/STAT pathway, agents that selectively perturb specific family members are being sought.

Figures adapted by kind permission of Cell Signaling Technology (http:// cellsignal.com)

\section{REFERENCES}

Arbouzova NI, Zeidler MP. 2006. JAK/STAT signalling in Drosophila: Insights into conserved regulatory and cellular functions. Development 133: $2605-2616$.

Darnell JE Jr, Kerr IM, Stark GR. 1994. Jak-STAT pathways and transcriptional activation in response to IFNs and other extracellular signaling proteins. Science 264: 1415-1421.
Dawson MA, Bannister AJ, Gottgens B, Foster SD, Bartke T, Green AR, Kouzarides T. 2009. JAK2 phosphorylates histone H3Y41 and excludes HP1a from chromatin. Nature 461: 819-822.

Ghoreschi K, Laurence A, O'Shea JJ. 2009. Janus kinases in immune cell signaling. Immunol Rev 228: 273-287.

Haan C, Behrmann I, Haan S. 2010. Perspectives for the use of structural information and chemical genetics to develop inhibitors of Janus kinases. J Cell Mol Med 14: 504-527.

Jatiani SS, Baker SJ, Silverman LR, Reddy EP. 2010. JAK/STAT pathways in cytokine signaling and myeloproliferative disorders: Approaches for targeted therapies. Genes Cancer 1: 979-993.

Li WX. 2008. Canonical and non-canonical JAK-STAT signaling. Trends Cell Biol 18: 545-551.

Pesu M, Laurence A, Kishore N, Zwillich SH, Chan G, O'Shea JJ. 2008. Therapeutic targeting of Janus kinases. Immunol Rev 223: 132-142.

Schindler C, Plumlee C. 2008. Inteferons pen the JAK-STAT pathway. Semin Cell Dev Biol 19: 311-318. 


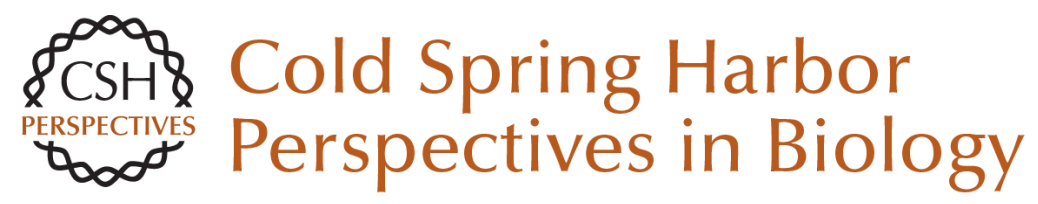

\section{The JAK/STAT Pathway}

Douglas A. Harrison

Cold Spring Harb Perspect Biol 2012; doi: 10.1101/cshperspect.a011205

Subject Collection Signal Transduction

Cell Signaling and Stress Responses Gökhan S. Hotamisligil and Roger J. Davis

Protein Regulation in Signal Transduction Michael J. Lee and Michael B. Yaffe

Synaptic Signaling in Learning and Memory Mary B. Kennedy

Vertebrate Reproduction Sally Kornbluth and Rafael Fissore

Signaling in Lymphocyte Activation Doreen Cantrell

Signaling in Muscle Contraction Ivana Y. Kuo and Barbara E. Ehrlich

Toll-Like Receptor Signaling Kian-Huat Lim and Louis M. Staudt

Signaling Pathways that Regulate Cell Division Nicholas Rhind and Paul Russell
Second Messengers

Alexandra C. Newton, Martin D. Bootman and John D. Scott

Signals and Receptors Carl-Henrik Heldin, Benson Lu, Ron Evans, et al.

Cell Death Signaling Douglas $R$. Green and Fabien Llambi

Signaling Networks that Regulate Cell Migration Peter Devreotes and Alan Rick Horwitz

Signaling Networks: Information Flow, Computation, and Decision Making Evren U. Azeloglu and Ravi lyengar

Signal Transduction: From the Atomic Age to the Post-Genomic Era Jeremy Thorner, Tony Hunter, Lewis C. Cantley, et al.

Signaling by the TGF $\beta$ Superfamily Jeffrey L. Wrana

Subversion of Cell Signaling by Pathogens Neal M. Alto and Kim Orth

For additional articles in this collection, see http://cshperspectives.cshlp.org/cgi/collection/

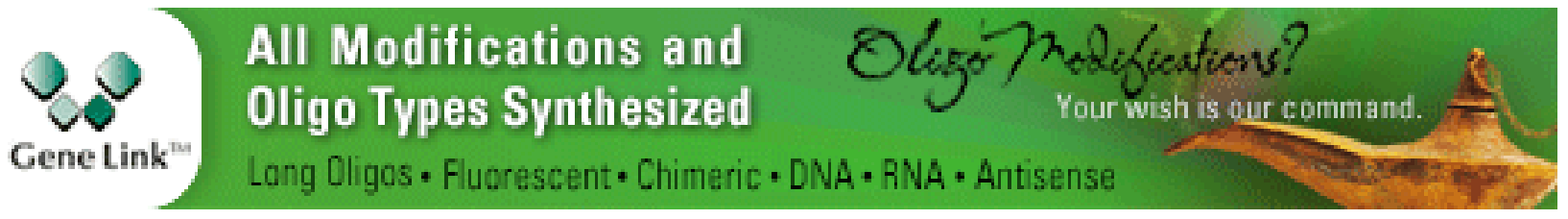

Copyright @ 2012 Cold Spring Harbor Laboratory Press; all rights reserved 